6 OPEN ACCESS

'Department of Ophthalmology, Eerste River and Groote Schuur Hospitals, University of Cape Town, Cape Town, South Africa 'Department of Ophthalmology, Bradford Royal Infirmary,

Bradford, UK

${ }^{3}$ Department of Ophthalmology, St Thomas' Hospital, London, UK

Correspondence to Kin Sheng Lim, Department of Ophthalmology, St Thomas' Hospital, London SE1 7EH, UK. shenglim@gmail.com

Received 30 October 2017 Revised 5 April 2018

Accepted 12 May 2018

Published Online First

4 July 2018

Check for updates

(c) Author(s) (or their employer(s)) 2018. Re-use permitted under CC BY-NC. No commercial re-use. See rights and permissions. Published by BMJ.

To cite: Steven DW,

Alaghband P, Lim KS

Br J Ophthalmol

2018:102:1497-1503.

\title{
Preservatives in glaucoma medication
}

\author{
David W Steven, ${ }^{1}$ Pouya Alaghband, ${ }^{2}$ Kin Sheng Lim ${ }^{3}$
}

\section{ABSTRACT}

Preservatives continue to be in widespread use in ophthalmic medications due to the convenience they provide, regulatory requirements and the higher cost of alternatives. Benzalkonium chloride (BAK) remains the most commonly used preservative but there is a trend towards the use of preservative-free (PF) drops for glaucoma, although at a higher price. An extensive body of literature explores BAK toxicity on ocular structures in animal and laboratory studies (in vitro and in vivo). Non-randomised controlled studies have provided some supporting evidence of its toxicity in patients, especially in those with pre-existing ocular surface disease (OSD) or on multiple medications. However, there have been very few randomised controlled trials that compare the same medication with and without BAK preservative. Several of these trials have never been published in any peer reviewed journals. Notwithstanding, those that have been published, have not demonstrated any clear benefits of the BAK-free formulations. Short duration and exclusion of those with OSD are limitations of these studies. There is a lack of evidence of clinically significant harm from a small number of BAK preserved drops in patients without OSD. This means that generally more expensive PF glaucoma medications should only be recommended for those on poly pharmacy or those with OSD but are not necessarily required for all patients.

\section{INTRODUCTION}

The use of preservatives extends the shelf-life of medications considerably. Patients would be able to administer their drops in a convenient and cost-effective way by allowing one large bottle of drops to last for a whole month. Their use has been a requirement in multidose containers by many regulatory authorities since the 1970s. ${ }^{1}$ Benzalkonium chloride (BAK) has been used in ophthalmology since the 1940s. It is by far the most common preservative, found in approximately $70 \%$ of eye drops. ${ }^{23}$ It is used in different concentrations varied from $0.004 \%$ to $0.02 \%$. It is a quaternary ammonium compound that acts as a detergent, lysing cell membranes and thus killing microorganisms. It is highly effective as a preservative. It was also initially thought that the detergent effect of BAK might be necessary for the penetration of the active ingredient. ${ }^{4}$

\section{Other preservatives and available alternatives}

Concern over the toxicity of BAK has led to other classes of preservatives being developed (table 1). These include polyquaternium-1 (Polyquad) which is a detergent, the oxidising preservatives such as Stabilised Oxychloro Complex (SOC, trade name Purite) and Sodium perborate (GenAqua) and the ionic buffered preservative SofZia. Additionally, advances in bottle design have created new dispensing mechanisms (such as COMOD or $\mathrm{ABAK}$ ) that allow longer lasting preservative-free (PF) bottles. However, these are not widely available. Furthermore, there is a trend towards unitdose preparations of glaucoma drops to eliminate the need for preservatives. ${ }^{5}$ Common preserved and PF glaucoma medications (drops) currently available in the UK are summarised in tables 2 and 3.

\section{Search strategy}

A 'PubMed' search was performed using the terms 'glaucoma medication' and 'preservative'. Randomised double-blind controlled clinical trials were sought within the results, of which only three comparing the same medication with and without preservative were selected. Other studies of interest are also discussed. We searched 'glaucoma' and 'preservative' terms on 'ClinicalTrial.gov' website in order to identify unpublished clinical trials.

\section{Preservative toxicity}

The laboratory and animal studies on the negative effects of BAK on the ocular structures have been the driving force against preservatives. Most of the literature concentrates on BAK as this is regarded as the most toxic and is the most commonly used. Other preservatives have been shown to exhibit less toxicity. ${ }^{67}$ In general, the antimicrobial activity of the preservative is inversely proportional to its compatibility with the ocular surface. ${ }^{6}$ Excipients (pharmacologically inactive substances acting as carriers for the active components), free radicals load and $\mathrm{pH}$ may also have an impact on the ocular surface. These parameter levels were found to be considerably variable between different glaucoma medications. $^{8}$

\section{BAK toxicity}

BAK has been demonstrated to have detrimental effects on many ocular structures including the conjunctival tissue and corneal epithelium as well as the trabecular meshwork and lens epithelium. ${ }^{910}$

\section{Conjunctiva}

Guenoun et al and several other studies found that at very low doses BAK induced proapoptotic effects on conjunctival epithelial cell lines. ${ }^{11-14}$ Notably though these studies did not demonstrate apoptotic effects from the active pressure-lowering compounds. In human subjects, prolonged exposure to multiple preserved glaucoma medications have been shown to produce inflammatory changes in the subepithelial conjunctiva, although reversible on cessation of the medication. However, 
Table 1 Commonly used preservatives in eye drops

\begin{tabular}{llll}
\hline Compound & Class & Antimicrobial action & Trade name \\
\hline BAK & Quaternary ammonium & Detergent action dissolves cell walls and membranes & Lumigan, Xalatan, etc \\
Polyquartenium 1 & Detergent & Acts on cell membranes & Tears Naturale II \\
SOC & Oxidising & Oxidation of intracellular lipids and glutathione & Alphagan P \\
Sodium perborate & Oxidising & Forms hydrogen peroxide, oxidising action similar to the above & GenAqua \\
$\begin{array}{l}\text { Borate, sorbitol, propylene } \\
\text { glycol and zinc }\end{array}$ & lonic buffer & Multiple & Genteal \\
\hline
\end{tabular}

BAK, benzalkonium chloride; SOC, Stabilised Oxychloro Complex.

comparisons have not been made with patients on PF medications. ${ }^{15} 16$ Leal et $a l^{17}$ examined the histology of patients with hyperaemia from bimatoprost (BAK $0.005 \%$ ). They concluded that it was not associated with inflammation, although this was after only 15-30 days use.

\section{Cornea}

Cell lines of three-dimensional corneal cells have shown similar apoptotic response to BAK, more so in superficial layers but in the deeper layers as well when apoptotic marker assays were used. ${ }^{18}$ However, other studies using the same three-dimensional model did not find any loss of cell viability. ${ }^{19}$ This highlights the difficulty of replicating studies using such models. In an animal model using in-vitro confocal microscopy, Liang found inflammatory infiltrates in the corneal epithelium, cellular swelling and desquamation from glaucoma medications, worst in those with BAK as a preservative. ${ }^{10}$

\section{Trabecular meshwork}

BAK is clearly toxic to trabecular meshwork cells. The laboratory studies have shown reduced cell numbers, growth and altered morphology ${ }^{20-22}$ and increased proapoptotic activity. ${ }^{23}$ An accumulation of BAK has been found in the trabecular meshwork of patients treated chronically (5-10 years) with BAK preserved medications. ${ }^{24}$ This has led to the hypothesis, yet unproven though, that chronic BAK exposure might worsen glaucoma. ${ }^{1}$

\section{Lens and other structures}

BAK has been shown to strongly induce the expression of inflammatory mediators in lens epithelial cells ${ }^{25}$ compared with latanoprost or timolol. The Blue Mountains Eye Study and Ocular Hypertension Treatment Study both suggested higher rates of cataract formation in those on antiglaucoma therapy. ${ }^{2627}$ Miyake $^{28}$ conducted studies that suggested that BAK preserved drops prior to cataract surgery increased the risk of cystoid

Table 2 Common glaucoma preparations available in preserved formulation

\begin{tabular}{|c|c|c|c|c|}
\hline \multicolumn{5}{|l|}{ Preserved drops } \\
\hline Medication & Brand name & Drug concentration & Preservative & $\begin{array}{l}\text { Preservative } \\
\text { concentration }\end{array}$ \\
\hline \multicolumn{5}{|l|}{ Prostaglandin analogues } \\
\hline Latanoprost & Xalatan & $50 \mu \mathrm{g} / \mathrm{mL}$ & Benzalkonium chloride & $0.02 \%$ \\
\hline Bimatoprost & Lumigan & 100 and $300 \mu \mathrm{g} / \mathrm{mL}$ & Benzalkonium chloride & $0.02 \%$ \\
\hline Travoprost & Travatan & $40 \mu \mathrm{g} / \mathrm{mL}$ & Polyquad & $0.01 \%$ \\
\hline \multicolumn{5}{|l|}{ Beta blockers } \\
\hline Timolol & Timolol and Timolol LA & 2.5 and $5 \mathrm{mg} / \mathrm{mL}$ & Benzalkonium chloride & $0.01 \%$ \\
\hline Levobunolol & Betagan & $5 \mathrm{mg} / \mathrm{mL}$ & Benzalkonium chloride & $0.004 \%$ \\
\hline Betaxolol & Betoptic & 2.5 and $5 \mathrm{mg} / \mathrm{mL}$ & Benzalkonium chloride & $0.01 \%$ \\
\hline \multicolumn{5}{|l|}{ Alpha blockers } \\
\hline Brimonidine & Alphagan & $2 \mathrm{mg} / \mathrm{mL}$ & Benzalkonium chloride & $0.005 \%$ \\
\hline Apraclonidine & lopidine & 5 and $10 \mathrm{mg} / \mathrm{mL}$ & $\begin{array}{l}\text { Benzalkonium chloride, } \\
\text { propylene glycol }\end{array}$ & $0.01 \%$ \\
\hline \multicolumn{5}{|l|}{ Carbonic anhydrase inhibitors } \\
\hline Brinzolamide & Azopt & $10 \mathrm{mg} / \mathrm{mL}$ & $\begin{array}{l}\text { Benzalkonium chloride, } \\
\text { disodium edetate }\end{array}$ & $0.01 \%$ \\
\hline Dorzolamide & Trusopt & $20 \mathrm{mg} / \mathrm{mL}$ & Benzalkonium chloride & $0.0075 \%$ \\
\hline \multicolumn{5}{|l|}{ Combinations } \\
\hline latanoprost $50 \mu \mathrm{g} / \mathrm{mL}$, timolol $5 \mathrm{mg} / \mathrm{mL}$ & Xalacom & & Benzalkonium chloride & $0.02 \%$ \\
\hline Lumigan $300 \mu \mathrm{g} / \mathrm{mL}$, timolol 5 mg/mL & Ganfort & & Benzalkonium chloride & $0.05 \%$ \\
\hline Travatan $40 \mu \mathrm{g}$, timolol $5 \mathrm{mg} / \mathrm{mL}$ & DuoTrav & & Polyquad & $0.01 \%$ \\
\hline Brinzolamide $10 \mathrm{mg} / \mathrm{mL}$, timolol $5 \mathrm{mg} / \mathrm{mL}$ & Azarga & & Benzalkonium chloride & $0.1 \%$ \\
\hline Dorzolamide $20 \mathrm{mg} / \mathrm{mL}$, timolol $5 \mathrm{mg} / \mathrm{mL}$ & Cosopt & & Benzalkonium chloride & $0.0075 \%$ \\
\hline Brimonidine $2 \mathrm{mg} / \mathrm{mL}$, Timolol $5 \mathrm{mg} / \mathrm{mL}$ & Combigan & & Benzalkonium chloride & $0.05 \%$ \\
\hline Brimonidine tartrate $2 \mathrm{mg} / \mathrm{mL}$, Brinzolamide $10 \mathrm{mg} / \mathrm{mL}$ & Simbrinza & & Benzalkonium chloride & $0.03 \%$ \\
\hline
\end{tabular}

Source: British National Formulary 2017. 


\begin{tabular}{lll}
\hline $\begin{array}{l}\text { Table } 3 \\
\text { preserved formulation }\end{array}$ & \multicolumn{1}{c}{ Common glaucoma preparations available in non- } \\
\hline Non-preserved & & \\
\hline Name of medication & Brand name & Drug concentration \\
\hline $\begin{array}{l}\text { Prostaglandin analogues } \\
\text { Latanoprost }\end{array}$ & Monopost & $0.005 \%$ \\
\hline Bimatoprost & Lumigan UD & $0.03 \%$ \\
\hline $\begin{array}{l}\text { Tafluprost } \\
\text { Beta blockers }\end{array}$ & Saflutan & $0.015 \%$ \\
\hline Timolol & Tiopex and Timoptol unit & $0.1 \%, 0.25 \%$ and $0.5 \%$ \\
\hline $\begin{array}{l}\text { Carbonic anhydrase } \\
\text { inhibitors }\end{array}$ & dose & \\
\hline Dorzolamide & Trusopt preservative free & $2 \%$ \\
\hline Combinations & & \\
\hline Bimatoprost/timolol & Ganfort UD & $0.03 \%, 0.5 \%$ \\
\hline Tafluprost/timolol & Taptiqom & $0.015 \%, 0.5 \%$ \\
\hline Dorzolamide/timolol & Cosopt preservative free & $2 \%, 0.5 \%$ \\
\hline
\end{tabular}

Source: British National Formulary 2017.

macular oedema. At a molecular level, DNA damage has been noted from BAK exposure in a dose-dependent fashion. ${ }^{29}$

\section{Clinical studies}

Clinically, the detergent properties of BAK can affect the lipid layer of the tear film, reducing tear breakup time (TBUT) and goblet cell numbers and mucin production are affected as well. ${ }^{3031}$ Many clinical studies have illustrated an increased level of corneal staining, reduced TBUT and other markers of ocular surface disease (OSD) with BAK preserved medications. ${ }^{32-34}$ OSD, to quote Batra et $a l,{ }^{35}$ is an 'umbrella term that includes dry eye, lid disease, conjunctivitis and keratitis'. While there are validated scoring systems for OSD such as the Ocular Surface Disease Index (OSDI) ${ }^{36}$ many studies used different subjective measures to evaluate the frequency and severity of OSD.

A French survey of over 4000 patients found those on PF drops had roughly half the symptoms and signs of OSD compared with those using preserved drops. ${ }^{33}$ Additionally, they demonstrated a large reduction of symptoms and signs on reducing the dose of preservatives or switching to PF. However, other clinical studies have found little or no corneal toxicity from various concentrations of BAK. A meta-analysis concluded that no significant difference in corneal staining occurred in patients that had twice the dose of BAK per day as others. Furthermore, BAK containing drops did not produce significant corneal toxicity in the vast majority of patients. ${ }^{37}$

\section{Published randomised controlled trials}

Overall studies that suggest more frequent adverse effects on those individuals who are on preserved medications have not been double masked ${ }^{38}$ or have not compared the same preserved and non-preserved medications. ${ }^{39}{ }^{40}$ There have been a very few double masked randomised controlled clinical trials (RCTs) published which PF drops are directly compared with the same drop containing preservative. An analysis of bias using the Cochrane review process was done and the following three RCTs were assessed as low risk. Briefly the randomisation processes were described, the two different medications in each study were dispensed in identical bottles and the investigators and patients were masked as to the study medication. Outcome data short and longer term was close to complete for all patients with $96 \%-98 \%$ of patients completing the studies with results reported.

These studies are summarised in table 4 .

Shedden et al reported in a double-masked study of 261 patients who were randomised 1:1 to either a PF combination of dorzolamide/timolol or one containing BAK at $0.0075 \%$ concentration. ${ }^{41}$ All patients had either ocular hypertension (OHT) or primary open-angle glaucoma (POAG). Efficacy was assessed by intraocular pressure (IOP) measurements done after a 3-week lead in on timolol alone and then at 2, 6 and 12 weeks after treatment with either PF or preserved dorzolamide/timolol combination. Tolerability was assessed by reported adverse events (AEs) by patients and objective clinical assessment. The efficacy of both preparations of dorzolamide/timolol was found to be equivalent at all time points. Overall both formulations were well tolerated. No statistical difference was found in terms of AEs between the two formulations. Furthermore, a similar percentage in each group had punctate epithelial erosions on examination $(23.8 \%$ preserved vs $16.8 \% \mathrm{PF})$. Three patients in the BAK group and four in the PF group discontinued their medication due to adverse effects.

Day et al in a double-masked randomised clinical trial, compared bimatoprost $0.03 \%$ PF with bimatoprost $0.03 \%$ containing BAK at a concentration of $0.005 \% .{ }^{42}$ They randomised just under 600 patients with $\mathrm{OHT}$ and various types of glaucoma. Those on other chronic ocular medication or with ocular surface findings were excluded, although hyperaemia was the only such finding which was specified. The duration of treatment was 12 weeks with evaluations at baseline, 2, 6 and 12 weeks. There was no statistically or clinically significant difference between the two formulations in terms of tolerability. Ocular AEs occurred in 32\% of the PF group (two of whom stopped treatment) and $35 \%$ of the BAK group (three of whom stopped). Hyperaemia rate, pruritus and punctate keratitis were almost identical, although more severe staining was slightly more common in the BAK group at $6.8 \%$ vs $3.7 \%(\mathrm{p}=0.086)$. Foreign body sensation occurred more in the PF group (seven patients, $2.3 \%$ ) than in the BAK group, (two patients, $0.7 \%$ ). The efficacy of medications was similar in both groups.

Goldberg et al compared bimatoprost $0.03 \% /$ timolol $0.5 \%$ PF with BAK $(0.005 \%)$ preserved formulation. ${ }^{43}$ Five hundred and sixty-one patients with either OHT or POAG were randomised. Those with chronic use of other ocular medication or with ocular surface findings (only hyperaemia or irritation were mentioned) were excluded. This was a double-masked RCT which was conducted for 12 weeks following a washout period of 4-28 days (depending on their medication). Safety was evaluated by self-reported adverse effects, slit lamp examination and grading of conjunctival hyperaemia based on the Oxford hyperaemia scoring system. Both formulations were safe and well tolerated. Treatment-related AEs (table 4) were reported in $28.8 \%$ in the PF group and $28.7 \%$ in the BAK group. Conjunctival hyperaemia was the most common $\mathrm{AE}$ which was usually mild. No significant difference was found between the two groups in terms of conjunctival hyperaemia, pruritus, dry eye, eye pain, eye lash growth and eyelid erythema. Skin hyperpigmentation was significantly more common in those on the PF formulation ( $4 \%$ vs $1.1 \%, \mathrm{p}=0.028)$, a finding that was thought to be incidental.

\section{Efficacy}

In all three aforementioned studies, the IOP lowering effect of the PF medications was non-inferior to the preserved preparation, 
Table 4 Ocular adverse effects of preserved vs PF medications in RCTs

\begin{tabular}{|c|c|c|c|c|c|c|}
\hline \multirow[b]{2}{*}{ AEs } & \multicolumn{2}{|l|}{ Sheddon } & \multicolumn{2}{|l|}{ Day } & \multicolumn{2}{|c|}{ Goldberg } \\
\hline & $\mathrm{PF}$ & BAK & PF & BAK & PF & BAK \\
\hline Overall \% & Not reported & Not reported & Not reported & Not reported & 33.1 & 33.7 \\
\hline Conjunctival hyperaemia & Not reported & Not reported & 23.9 & 26.1 & 21.2 & 19.5 \\
\hline Mild & Not reported & Not reported & 17.6 & 21 & 16.5 & 15.6 \\
\hline Moderate & Not reported & Not reported & 6.3 & 4.4 & 4.0 & 3.9 \\
\hline Severe & Not reported & Not reported & 0 & 0.7 & 0.7 & 0 \\
\hline Pruritus & Not reported & Not reported & 4.0 & 4.1 & 4.3 & 1.8 \\
\hline Skin pigmentation & Not reported & Not reported & Not reported & Not reported & 4 & 1.4 \\
\hline Dry eye & Not reported & Not reported & 1.7 & 3.1 & 3.2 & 1.1 \\
\hline Punctate keratitis & 16.8 & 23.8 & 3.0 & 3.1 & 2.9 & 2.5 \\
\hline Eye pain & Not reported & Not reported & Not reported & Not reported & 2.5 & 1.8 \\
\hline Foreign body sensation & Not reported & Not reported & 2.3 & 0.7 & 2.2 & 2.1 \\
\hline Eye irritation & 16 & 21.5 & Not reported & Not reported & 2.2 & 1.8 \\
\hline Eyelash growth & Not reported & Not reported & Not reported & Not reported & 1.4 & 2.8 \\
\hline Erythema & Not reported & Not reported & Not reported & Not reported & 1.1 & 2.5 \\
\hline Discontinuation due to ocular AE (by patients) & 4 & 3 & 2 & 3 & 4 & 9 \\
\hline
\end{tabular}

AEs, adverse events; $B A K$, benzalkonium chloride; $P F$, preservative-free; $R C T$, randomised controlled trials.

indicating that BAK is not required for adequate drug penetration, in line with other studies demonstrating equivalent efficacy between BAK preserved and PF glaucoma medications. ${ }^{44}$

\section{Unpublished randomised controlled trials}

Several moderately sized RCT have been carried out comparing BAK preserved medications to those with alternative preservatives. Unpublished studies with reported results available are summarised in table 5 .

However, no statistical analysis of the results had been attempted. It is not clear why these studies were not formally published. It could be speculated that it may have been due to the lack of clinically significant difference found between the medications being compared.

\section{Patient satisfaction}

Ultimately, glaucoma treatment can only be successful, if it is used by patients, thus compliance is a significant issue. Treatment satisfaction has been identified as an important factor to improve compliance ${ }^{45}$.

Rouland et $a l^{38}$ randomised over 400 patients to either preserved or PF latanoprost in an investigator-masked study. After 12 weeks, hyperaemia was worse in the preserved group as was the total objective ocular symptom score. However, there was no difference in the other objective signs (such as corneal staining). Furthermore, tolerance was reported as satisfactory or very satisfactory in more than $97 \%$ of patients in both groups. A survey of over 2500 patients in New Zealand ${ }^{45}$ reported high levels of satisfaction that was associated with the frequency of drops, convenience and ease of use. The presence of side effects was not predictive of the level of satisfaction. The only side effect which was significantly greater than control group (not on medication) was hyperaemia. A recent survey by Lemij et al found a high treatment satisfaction rate among patients despite the presence of OSD signs, ${ }^{46}$ though hyperaemia and ocular discomfort were the factors associated with dissatisfaction.

\section{Preservatives in established OSD}

In patients with established OSD, switching to PF medications have been shown to be beneficial to improve their symptoms, signs and tolerability. Uusitalo et $a l^{39}$ in a study of those with pre-existing signs or symptoms of OSD found that symptoms after switching to tafluprost PF were reduced to one-third of baseline of latanoprost BAK preserved and signs were reduced by half. This study was limited by its open label nature and comparison of different prostaglandin analogues (rather than the same type of medication). In a randomised, double-masked, prospective study, Katz et $a l^{40}$ found that switching to travoprost PF from preserved latanoprost in those with some OSD (mild or worse) also led to some symptom relief in those with mild OSD and in the subgroup with prior preserved drop use of more than 24 months. The corneal staining between the two groups was similar after 12 weeks. Interestingly there was more eye pain, irritation and hyperaemia in the PF group noted. Janulevičiene et $a l^{34}$ measured tear film osmolarity before and after switching from BAK preserved latanoprost to tafluprost PF in patients with

Table 5 Unpublished data from https://clinicaltrials.gov website

\begin{tabular}{|c|c|c|c|c|c|}
\hline $\begin{array}{l}\text { Comparison } \\
\text { (ClinicalTrial.gov identifier) }\end{array}$ & Year & $\begin{array}{l}\text { Duration } \\
\text { (months) }\end{array}$ & Number of patients & Study type & Results \\
\hline $\begin{array}{l}\text { Travoprost (sofZia) vs Latanoprost BAK } \\
\text { (NCT00798759) }\end{array}$ & 2008 & 3 & 215 & Double masked RCT & $\begin{array}{l}\text { OSDI score slightly better with SofZia } \\
\text { TBUT the same }\end{array}$ \\
\hline $\begin{array}{l}\text { Travoprost (sofZia) vs Latanoprost BAK } \\
\text { (NCT00690794) }\end{array}$ & 2008 & 3 & 726 & Double masked RCT & $\begin{array}{l}\text { OSDI change similar } \\
\text { Absence of corneal staining similar } \\
\text { ( } 37 \text { sofZia, } 40 \text { BAK) }\end{array}$ \\
\hline $\begin{array}{l}\text { Travoprost (sofZia) vs Latanoprost BAK } \\
\text { (NCT00527592) }\end{array}$ & 2007 & Not stated & $\begin{array}{l}54 \text { (comparison made } \\
\text { between eyes) }\end{array}$ & Double masked RCT & Comfort after dose equal \\
\hline
\end{tabular}

BAK, benzalkonium chloride; OSDI, Ocular SurfaceDisease Index; RCT, randomised controlled trials; TBUT, tear breakup time. 
pre-existing OSD. They found significant improvement in tear film osmolarity as well as TBUT and corneal staining.

Batra et $a l^{35}$ reported on patients with severe OSD and inadequately controlled glaucoma. They demonstrated that controlling the OSD resulted in improvement in OSD and IOP control. Measures used included lid hygiene, topical lubricants, oral doxycycline and switching to PF medications.

Skalicky et $a l^{47}$ found that the use of more than three glaucoma medications was an independent predictor of adverse OSDI score.

\section{Causes of variability between laboratory and clinical studies}

The severity of BAK toxicity in laboratory studies and the variability in the effect found in clinical studies may partly be due to the extended duration of exposure in many of the in-vitro and in-vivo studies. In fact, clinically the concentration of BAK in the tear film diminishes very rapidly. ${ }^{48}$

Chemical binding reduces the amount of free BAK. Additionally, the antioxidant effect of prostaglandin analogues may explain the relatively high tolerance of such medications in the longer term. ${ }^{11} \mathrm{~A}$ study of conjunctival goblet cell density $(\mathrm{CGCD})^{49}$ found that tafluprost PF and preserved latanoprost both caused increased CGCD at 1 month. There was a sustained increase of CGCD in the tafluprost group at 6 months. This was not reversed by switching to preserved latanoprost. However, those treated with the latanoprost vehicle alone had a significant decrease. TBUT and Schirmer tests were very similar between two groups. The PF group had a lower OSDI score but were not masked to their treatment (a possible source of bias). Different prostaglandin analogues may also differ in their protective properties. 7

There is some evidence to suggest BAK exposure may reduce corneal sensitivity and thus symptoms. ${ }^{50}$ Furthermore, the effect of tear film osmolality in increasing BAK concentration may also explain why patients with pre-existing OSD/dry eye are more at risk. $^{51}$

\section{BAK effect on glaucoma surgical success}

\section{Trabeculectomy}

A small number of studies have examined the effect of prior medical treatment on trabeculectomy success and even fewer have tried to look at the effect of BAK in particular. Broadway et $a l^{52}$ explored the outcome of 124 trabeculectomies. They found that a higher rate of failure was associated with long-term usage of multiple medications (all preserved, including miotics and sympathomimetics that are seldom used nowadays) and corresponding subclinical inflammatory changes in the conjunctiva. Boimer and Birt $^{53}$ in a retrospective study examined the results of 128 trabeculectomies. They compared BAK exposure using the number of BAK containing drops as a proxy and the dose corrected BAK exposure per day (adjusting for varying concentrations of BAK in different drops). Those with a higher number of preoperative drops and a higher dose corrected exposure had a higher risk of early trabeculectomy failure. It was not possible to calculate the cumulative dose of BAK received in each patient. However, another study of 215 trabeculectomies ${ }^{54}$ did not find an association between the number of medications used or length of usage and trabeculectomy failure. Another study explored tear cytokines ${ }^{55}$ demonstrated elevated levels of an inflammatory mediator (monocyte chemoattractant protein-1 (MCP-1)) in patients taking glaucoma medications. Higher levels of MCP-1 were found with longer duration of medication use (mostly BAK preserved). Additionally, a greater risk of requiring post

\begin{tabular}{|c|c|c|c|}
\hline Medication & $\mathrm{PF}$ & Preserved & Premium, \% \\
\hline Bimatoprost $0.03 \%$ & f13.75 & f10.30 & 34 \\
\hline Bimatoprost/Timolol & f17.94 & f14.16 & 27 \\
\hline Latanoprost & f8.49 & f1.43 (generic) & 493 \\
\hline Dorzolamide/Timolol & f28.59 & f1.65 (generic) & 1633 \\
\hline
\end{tabular}

$\mathrm{PF}$, preservative-free.

trabeculectomy intervention due to higher MCP-1 level was noted. However, there was no association between the number of medications and the higher risk.

PF prostaglandin analogues have been found to induce ocular adnexa macrophage infiltration, which may be partially explained by excipients in the medications. ${ }^{56}$ Other common adverse effects of prostaglandin analogues such as orbitopathy ${ }^{57}$ are not attributed to their preservatives. A recent Japanese study found better IOP control post-trabeculectomy in those patients who did not exhibit signs of orbitopathy due to preoperative prostaglandin analogues. ${ }^{58}$

Broadway reported that withdrawing medications 4 weeks prior to trabeculectomy surgery and administering low potency topical steroids (fluorometholone) reduced conjunctival inflammation. ${ }^{59}$ Breusegem reported the successful use of preoperative anti-inflammatory medications (steroids and to a lesser extent non-steroidal anti-inflammatories) to improve failure rates of trabeculectomy surgery. ${ }^{60}$

\section{Glaucoma aqueous shunt surgery and MIGS (minimally invasive} glaucoma surgery)

No studies have examined the effects of prior glaucoma medications or preservative use on the success rate of tube surgery or MIGS procedures.

\section{Cost issues}

In general, PF preparations cost much more than the equivalent with preservative (table 6) (British National Formulary 2017). ${ }^{61}$ The premium charged by the manufacturers for the PF glaucoma medications range from $27 \%$ to over $1600 \%$, compared with the same medications with preservatives.

From a cost effectiveness perspective, studies have linked patient satisfaction and fewer medication changes with lower costs. ${ }^{62}$ However, there have not been any studies directly comparing the cost effectiveness of preserved versus PF medications.

\section{Other preservatives}

While there are no clinical studies comparing non- BAK preserved drops to PF drops, there have been comparisons between nonBAK preserved and BAK preserved.

Gandolfi et $a l^{63}$ randomised 371 patients to receive either BAK or polyquad preserved travoprost. At 3 months, adverse effects were generally mild and very similar in both groups.

Peace et $a l^{64}$ compared travoprost $0.03 \%$ with polyquad to BAK preserved travoprost $0.04 \%$ and found no difference in adverse effects (a slight increase in hyperaemia in the BAK preparation group may have been related to the higher travoprost concentration). More recently Jayanthi et $a l^{65}$ published a comparison of BAK preserved travoprost with SofZia preserved. They reported significantly lower OSDI scores in patients on the SofZia preserved formulation. However, this study was open-labelled which may have caused some bias. 


\section{CONCLUSION/CLINICAL IMPLICATIONS}

Clearly topical medications, preservatives and the excipients and buffers can cause some ocular surface changes. Laboratory and non-level one evidence demonstrate additional adverse effects from BAK. There are no data available to demonstrate that the efficacy of glaucoma medications is reduced in the absence of BAK. There is also no evidence from double-masked RCTs that BAK causes significant OSD over and above the glaucoma medication alone in patients with a healthy ocular surface.

For those on polypharmacy or with OSD, the resultant cumulatively higher dose or concentration of BAK in the tear film may mean that preservative-free preparations are desirable in patients taking more than three medications or in those with pre-existing OSD. Symptoms and signs of toxicity should be screened for those on preserved drops, as there is some evidence suggesting that switching to PF drops will improve these.

There is no conclusive evidence that BAK per se jeopardises the success rate of glaucoma filtration surgery. For those who are likely to have glaucoma filtration surgery, minimising exposure to both topical agents and preservatives may be recommended. Whether this should be in the form of earlier surgery or a preoperative washout period remains to be elucidated. This is an area in which further research is required, particularly in light of less invasive surgical options emergence.

Current evidence is inadequate due to exclusion of patients with pre-existing OSD and the short duration of many other studies. Longer-term double-masked clinical trials comparing patients on PF drops versus preserved drops would be desirable. These may not be practical due to the high cost of such studies.

As clinicians dealing with ageing populations and ever-increasing number of glaucoma patients, we should be conscious of the cost repercussions of each treatment options. Based on current evidence there is no justification for routine use of PF medication in those without significant OSD and especially those requiring only few medications (1-2) per day.

Contributors KSL had the original idea for the article and is the guarantor. All other authors were involved in literature search, drafting, revising and final approval of the document.

Funding KSL is funded by the Biomedical Research Centre, Guy's \& ST Thomas' NHS Foundation Trust.

Competing interests KSL has received grant from the Thea pharmaceuticals and travel support and lecture/consultancy fees from Allergan, Alcon, MSD and Thea. He is also an investigator in prospective randomised controlled trials using preservativefree glaucoma medications funded by the Allergan, Thea and Santen. DWS does not have any competing interest. PA has received educational grants and lecture fees from Thea pharmaceutical.

\section{Patient consent Not required.}

Provenance and peer review Not commissioned; externally peer reviewed.

Data sharing statement There are no additional unpublished data from this study.

Open access This is an Open Access article distributed in accordance with the Creative Commons Attribution Non Commercial (CC BY-NC 4.0) license, which permits others to distribute, remix, adapt, build upon this work non-commercially, and license their derivative works on different terms, provided the original work is properly cited and the use is non-commercial. See: http://creativecommons.org/ licenses/by-nc/4.0/

\section{REFERENCES}

1 Rasmussen CA, Kaufman PL, Kiland JA. Benzalkonium chloride and glaucoma. J Ocul Pharmacol Ther 2014;30:163-9.

2 Freeman PD, Kahook MY. Preservatives in topical ophthalmic medications: historical and clinical perspectives. Expert Rev Ophthalmol 2009;4:59-64.

3 Broadway DC, Grierson I, O'Brien C, et al. Adverse effects of topical antiglaucoma medication. II. The outcome of filtration surgery. Arch Ophthalmol 1994;112:1446-54.
4 Baudouin C, Labbé A, Liang H, et al. Preservatives in eyedrops: the good, the bad and the ugly. Prog Retin Eye Res 2010;29:312-34.

5 Anwar Z, Wellik SR, Galor A. Glaucoma therapy and ocular surface disease: current literature and recommendations. Curr Opin Ophthalmol 2013:24:136-43.

6 Tu EY. Balancing antimicrobial efficacy and toxicity of currently available topical ophthalmic preservatives. Saudi I Ophthalmol 2014;28:182-7.

7 Ammar DA, Noecker RJ, Kahook MY. Effects of benzalkonium chloride- and polyquadpreserved combination glaucoma medications on cultured human ocular surface cells. Adv Ther 2011;28:501-10.

8 Lockington D, Macdonald EC, Stewart P, et al. Free radicals and the $\mathrm{pH}$ of topical glaucoma medications: a lifetime of ocular chemical injury? Eye 2012;26:734-41.

9 Pellinen $\mathrm{P}$, Huhtala A, Tolonen A, et al. The cytotoxic effects of preserved and preservative-free prostaglandin analogs on human corneal and conjunctival epithelium in vitro and the distribution of benzalkonium chloride homologs in ocular surface tissues in vivo. Curr Eye Res 2012;37:145-54.

10 Liang H, Pauly A, Riancho L, et al. Toxicological evaluation of preservativecontaining and preservative-free topical prostaglandin analogues on a three-dimensional-reconstituted corneal epithelium system. Br J Ophthalmol 2011:95:869-75.

11 Guenoun JM, Baudouin C, Rat P, et al. In vitro comparison of cytoprotective and antioxidative effects of latanoprost, travoprost, and bimatoprost on conjunctivaderived epithelial cells. Invest Ophthalmol Vis Sci 2005;46:4594-9.

12 Pisella PJ, Debbasch C, Hamard P, et al. Conjunctival proinflammatory and proapoptotic effects of latanoprost and preserved and unpreserved timolol: an ex vivo and in vitro study. Invest Ophthalmol Vis Sci 2004:45:1360-8.

13 Guenoun JM, Baudouin C, Rat P, et al. In vitro study of inflammatory potential and toxicity profile of latanoprost, travoprost, and bimatoprost in conjunctiva-derived epithelial cells. Invest Ophthalmol Vis Sci 2005b;46:2444-50.

14 Brasnu E, Brignole-Baudouin F, Riancho L, et al. In vitro effects of preservative-free tafluprost and preserved latanoprost, travoprost, and bimatoprost in a conjunctival epithelial cell line. Curr Eye Res 2008;33:303-12.

15 Broadway DC, Grierson I, O'Brien C, et al. Adverse effects of topical antiglaucoma medication. I. The conjunctival cell profile. Arch Ophthalmol 1994;112:1437-45.

16 Liesegang TJ. Conjunctival changes associated with glaucoma therapy: implications for the external disease consultant and the treatment of glaucoma. Cornea 1998; 17:574-83.

17 Leal BC, Medeiros FA, Medeiros FW, et al. Conjunctival hyperemia associated with bimatoprost use: a histopathologic study. Am J Ophthalmol 2004;138:310-3.

18 Pauly A, Meloni M, Brignole-Baudouin $F$, et al. Multiple endpoint analysis of the 3D-reconstituted corneal epithelium after treatment with benzalkonium chloride: early detection of toxic damage. Invest Ophthalmol Vis Sci 2009;50:1644-52.

19 Khoh-Reiter S, Jessen BA. Evaluation of the cytotoxic effects of ophthalmic solutions containing benzalkonium chloride on corneal epithelium using an organotypic 3-D model. BMC Ophthalmol 2009;9:5.

20 Samples JR, Binder PS, Nayak S. The effect of epinephrine and benzalkonium chloride on cultured corneal endothelial and trabecular meshwork cells. Exp Eye Res 1989;49:1-12

21 Kawa JE, Higginbotham EJ, Chang IL, et al. Effects of antiglaucoma medications on bovine trabecular meshwork cells in vitro. Exp Eye Res 1993;57:557-65.

22 Tripathi BJ, Tripathi RC, Millard CB. Epinephrine-induced toxicity of human trabecular cells in vitro. Lens Eye Toxic Res 1989;6:141-56.

23 Hamard P, Blondin C, Debbasch C, et al. In vitro effects of preserved and unpreserved antiglaucoma drugs on apoptotic marker expression by human trabecular cells. Graefes Arch Clin Exp Ophthalmol 2003:241:1037-43.

24 Desbenoit N, Schmitz-Afonso I, Baudouin C, et al. Localisation and quantification of benzalkonium chloride in eye tissue by TOF-SIMS imaging and liquid chromatography mass spectrometry. Anal Bioanal Chem 2013:405:4039-49.

25 Goto Y, Ibaraki N, Miyake K. Human lens epithelial cell damage and stimulation of their secretion of chemical mediators by benzalkonium chloride rather than latanoprost and timolol. Arch Ophthalmol 2003;121:835-9.

26 Herman DC, Gordon MO, Beiser JA, et al. Topical ocular hypotensive medication and lens opacification: evidence from the ocular hypertension treatment study. Am J Ophthalmol 2006;142:800-10.

27 Chandrasekaran S, Cumming RG, Rochtchina E, et al. Associations between elevated intraocular pressure and glaucoma, use of glaucoma medications, and 5-year incident cataract: the Blue Mountains Eye Study. Ophthalmology 2006;113:417-24.

28 Miyake K, Ibaraki N, Goto Y, et al. ESCRS Binkhorst lecture 2002: Pseudophakic preservative maculopathy. J Cataract Refract Surg 2003;29:1800-10.

$29 \mathrm{Ye} \mathrm{J,} \mathrm{Wu} \mathrm{H,} \mathrm{Zhang} \mathrm{H,} \mathrm{et} \mathrm{al.} \mathrm{Role} \mathrm{of} \mathrm{benzalkonium} \mathrm{chloride} \mathrm{in} \mathrm{DNA} \mathrm{strand} \mathrm{breaks} \mathrm{in}$ human corneal epithelial cells. Graefes Arch Clin Exp Ophthalmol 2011;249:1681-7.

30 Pisella PJ, Fillacier K, Elena PP, et al. Comparison of the effects of preserved and unpreserved formulations of timolol on the ocular surface of albino rabbits. Ophthalmic Res 2000;32:3-8.

31 Herreras JM, Pastor JC, Calonge M, et al. Ocular surface alteration after long-term treatment with an antiglaucomatous drug. Ophthalmology 1992;99:1082-8.

32 Jaenen $\mathrm{N}$, Baudouin $\mathrm{C}$, Pouliquen $\mathrm{P}$, et al. Ocular symptoms and signs with preserved and preservative-free glaucoma medications. Eur J Ophthalmol 2007;17:341-9. 
33 Pisella PJ, Pouliquen P, Baudouin C. Prevalence of ocular symptoms and signs with preserved and preservative free glaucoma medication. Br J Ophthalmol 2002;86:418-23.

34 Janulevičienè I, Derkač I, Grybauskiene L, et al. Effects of preservative-free tafluprost on tear film osmolarity, tolerability, and intraocular pressure in previously treated patients with open-angle glaucoma. Clin Ophthalmol 2012;6:103-9.

35 Batra R, Tailor R, Mohamed S. Ocular surface disease exacerbated glaucoma: optimizing the ocular surface improves intraocular pressure control. J Glaucoma 2014;23:56-60.

36 Schiffman RM, Christianson MD, Jacobsen G, et al. Reliability and validity of the Ocular Surface Disease Index. Arch Ophthalmol 2000;118:615-21.

37 Trocme S, Hwang LJ, Bean GW, et al. The role of benzalkonium chloride in the occurrence of punctate keratitis: a meta-analysis of randomized, controlled clinical trials. Ann Pharmacother 2010;44:1914-21.

38 Rouland JF, Traverso CE, Stalmans I, et al. Efficacy and safety of preservative-free latanoprost eyedrops, compared with BAK-preserved latanoprost in patients with ocular hypertension or glaucoma. Br J Ophthalmol 2013;97:196-200.

39 Uusitalo H, Egorov E, Kaarniranta K, et al. Benefits of switching from latanoprost to preservative-free tafluprost eye drops: a meta-analysis of two Phase IIIb clinical trials. Clin Ophthalmol 2016;10:445-54.

40 Katz G, Springs CL, Craven ER, et al. Ocular surface disease in patients with glaucoma or ocular hypertension treated with either BAK-preserved latanoprost or BAK-free travoprost. Clin Ophthalmol 2010;4:1253-61.

41 Shedden A, Adamsons IA, Getson AJ, et al. Comparison of the efficacy and tolerability of preservative-free and preservative-containing formulations of the dorzolamide/timolol fixed combination (COSOPT'M) in patients with elevated intraocular pressure in a randomized clinical trial. Graefes Arch Clin Exp Ophthalmol 2010:248:1757-64.

42 Day DG, Walters TR, Schwartz GF, et al. Bimatoprost $0.03 \%$ preservative-free ophthalmic solution versus bimatoprost $0.03 \%$ ophthalmic solution (Lumigan) for glaucoma or ocular hypertension: a 12-week, randomised, double-masked trial. Br J Ophthalmol 2013;97:989-93.

43 Goldberg I, Gil Pina R, Lanzagorta-Aresti A, et al. Bimatoprost 0.03\%/timolol 0.5\% preservative-free ophthalmic solution versus bimatoprost $0.03 \% /$ timolol $0.5 \%$ ophthalmic solution (Ganfort) for glaucoma or ocular hypertension: a 12-week randomised controlled trial. Br J Ophthalmol 2014;98:926-31.

44 Hopes M, Broadway D, Department of Ophthalmology, Norfolk and Norwich University Hospita. Preservative-free treatment in glaucoma is a sensible and realistic aim for the future. European Ophthalmic Review 2010;04:23-8.

45 Kerr NM, Patel HY, Chew SS, et al. Patient satisfaction with topical ocular hypotensives. Clin Exp Ophthalmol 2013;41:27-35.

46 Lemij HG, Hoevenaars JG, van der Windt C, et al. Patient satisfaction with glaucoma therapy: reality or myth? Clin Ophthalmol 2015:9:785-93.

47 Skalicky SE, Goldberg I, McCluskey P. Ocular surface disease and quality of life in patients with glaucoma. Am J Ophthalmol 2012;153:1-9.

48 Friedlaender $\mathrm{MH}$, Breshears D, Amoozgar B, et al. The dilution of benzalkonium chloride (BAK) in the tear film. Adv Ther 2006;23:835-41.
49 Mastropasqua L, Agnifili L, Fasanella V, et al. Conjunctival goblet cells density and preservative-free tafluprost therapy for glaucoma: an in vivo confocal microscopy and impression cytology study. Acta Ophthalmol 2013;91:e397-e405.

50 Sarkar J, Chaudhary S, Namavari A, et al. Corneal neurotoxicity due to topical benzalkonium chloride. Invest Ophthalmol Vis Sci 2012;53:1792-802.

51 Clouzeau C, Godefroy D, Riancho L, et al. Hyperosmolarity potentiates toxic effects of benzalkonium chloride on conjunctival epithelial cells in vitro. Mol Vis 2012;18:851-63.

52 Broadway DC, Grierson I, Stürmer J, et al. Reversal of topical antiglaucoma medication effects on the conjunctiva. Ophthalmo/1996;114:262-7.

53 Boimer C, Birt CM. Preservative exposure and surgical outcomes in glaucoma patients: The PESO study. J Glaucoma 2013;22:730-5.

54 Öztürker ZK, Öztürker C, Bayraktar S, et al. Does the use of preoperative antiglaucoma medications influence trabeculectomy success? J Ocul Pharmacol Ther 2014;30:554-8.

55 Chong RS, Jiang YZ, Boey PY, et al. Tear cytokine profile in medicated glaucoma patients: effect of monocyte chemoattractant protein 1 on early posttrabeculectomy outcome. Ophthalmology 2010;117:2353-8.

56 Trzeciecka A, Paterno JJ, Toropainen E, et al. Long-term topical application of preservative-free prostaglandin analogues evokes macrophage infiltration in the ocular adnexa. Eur J Pharmacol 2016;788:12-20.

57 Kucukevcilioglu M, Bayer A, Uysal Y, et al. Prostaglandin associated periorbitopathy in patients using bimatoprost, latanoprost and travoprost. Clin Exp Ophthalmol 2014:42:126-31.

58 Miki T, Naito T, Fujiwara M, et al. Effects of pre-surgical administration of prostaglandin analogs on the outcome of trabeculectomy. PLoS One 2017;12:e0181550

59 Broadway DC, Grierson I, O'Brien C, et al. Adverse effects of topical antiglaucoma medication. II. The outcome of filtration surgery. Arch Ophthalmol 1994;112:1446-54.

60 Breusegem C, Spielberg L, Van Ginderdeuren R, et al. Preoperative nonsteroidal anti-inflammatory drug or steroid and outcomes after trabeculectomy: a randomized controlled trial. Ophthalmology 2010;117:1324-30.

61 British National Formulary (BNF). 72 edn: BMJ Publishing Group.

62 Denis P, University Professor, Hospital Consultant and Head, Ophthalmology Department, Croix-Rousse Hospital, Lyon, Professor U, U Consultant and Head, U, Croix-Rousse Hospital, $U$ and, . Adverse effects, adherence and cost-benefits in glaucoma treatment. Euro Ophthal Rev 2011;05:116-22.

63 Gandolfi S, Paredes T, Goldberg I, et al. Comparison of a travoprost BAK-free formulation preserved with polyquaternium-1 with BAK-preserved travoprost in ocula hypertension or open-angle glaucoma. Eur J Ophthalmol 2012;22:34-44.

64 Peace JH, Ahlberg P, Wagner M, et al. Polyquaternium-1-preserved travoprost $0.003 \%$ or benzalkonium chloride-preserved travoprost $0.004 \%$ for glaucoma and ocular hypertension. Am J Ophthalmol 2015;160:266-74.

65 Jayanthi CR, Divyashree RN, Sujatha BL. Efficacy and safety of topical BAK-free travoprost $0.004 \%$ versus BAK-preserved travoprost $0.004 \%$ in the treatment of primary open angle glaucoma: a comparative study at a tertiary care hospital. Int J Basic Clin Pharmacol 2017:6:2199-205. 